\title{
Oral octreotide capsules for the treatment of acromegaly: comparison of 2 phase 3 trial results
}

\author{
Artak Labadzhyan $^{1} \cdot$ L B Nachtigall ${ }^{2} \cdot$ M Fleseriu $^{3}$ (ID $\cdot M$ B Gordon ${ }^{4} \cdot$ M Molitch $^{5} \cdot$ L Kennedy $^{6} \cdot S$ L Samson ${ }^{7}$ (iD .

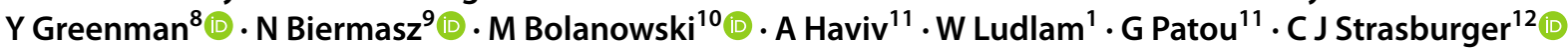

Accepted: 11 June 2021 / Published online: 25 June 2021

(C) The Author(s) 2021, corrected publication 2021

\begin{abstract}
Purpose Results are presented from 2 to 3 trials investigating oral octreotide capsules (OOC) as an alternative to injectable somatostatin receptor ligands (iSRLs) in the treatment of acromegaly.

Methods $\mathrm{CH}-\mathrm{ACM}-01$ was an open-label trial $(\mathrm{N}=155)$ and CHIASMA OPTIMAL was a double-blind placebo-controlled (DPC) trial $(\mathrm{N}=56)$, both investigating OOC as maintenance therapy for patients with acromegaly who were biochemical responders receiving iSRLs.

Results Baseline characteristics in both trials reflected those expected of patients with acromegaly responding to treatment and were similar between trials, despite differences in inclusion criteria. OOC demonstrated a consistent degree of biochemical response across trials, with $65 \%$ of patients in $\mathrm{CH}-\mathrm{ACM}-01$ maintaining response during the core period and $64 \%$ of patients in CHIASMA OPTIMAL at the end of the DPC. Mean insulin-like growth factor I (IGF-I) levels remained within inclusion criteria at the end of treatment in both trials. Of 110 patients entering the fixed-dose phase in CH-ACM- $01,80 \%$ maintained or improved acromegaly symptoms from baseline to the end of treatment. Over $85 \%$ of patients in both trials elected to continue into the extension phases. OOC were found to be well tolerated across both trials, and no dose-related adverse events were observed.

Conclusions OOC demonstrated remarkably consistent results for biochemical response, durability of response, and preference to continue with oral treatment across these 2 complementary landmark phase 3 trials, despite differences in the design of each.
\end{abstract}

Trial registration NCT03252353 (August 2017), NCT01412424 (August 2011).

Keywords Oral octreotide $\cdot$ Acromegaly $\cdot$ IGF-I $\cdot$ Somatostatin receptor ligands $\cdot$ Somatostatin analogs $\cdot$ Growth hormone

Artak Labadzhyan

Artak.Labadzhyan@cshs.org

1 Cedars-Sinai Medical Center, Los Angeles, CA 90048, USA

2 MGH Neuroendocrine and Pituitary Center, Chestnut Hill, MA, USA

3 Pituitary Center, Oregon Health \& Sciences University, Portland, OR, USA

4 Allegheny Neuroendocrinology Center, Allegheny General Hospital, Pittsburgh, PA, USA

5 Northwestern University, Chicago, IL, USA
6 Cleveland Clinic Foundation, Cleveland, OH, USA

7 Mayo Clinic, Jacksonville, FL, USA

8 Sourasky Medical Center and Tel Aviv University, Tel Aviv, Israel

9 Leiden University Medical Center, Leiden, The Netherlands

10 Wroclaw Medical University, Wroclaw, Poland

11 Chiasma, Inc., Needham, MA, USA

12 Charite Universitatsmedizin, Berlin, Germany 


\section{Introduction}

Acromegaly is characterized by excessive circulating levels of growth hormone $(\mathrm{GH})$ and insulin-like growth factor I (IGF-I), usually resulting from a GH-secreting pituitary adenoma [1-5]. Treatment for acromegaly is aimed at normalizing GH and IGF-I levels, shrinking tumors, amelioration of symptoms, improving quality of life, and reducing mortality with as few side effects as possible $[1,6,7]$. Pituitary surgery is the primary therapy for most patients with acromegaly $[1,2]$. For patients unwilling or unable to undergo surgery, or in patients with persistent or recurrent disease, medical therapy is indicated [2, 8, 9]. Medical therapy includes somatostatin receptor ligands (SRLs), GH receptor antagonists, and dopamine agonists in single or combination therapy $[10,11]$. Long-acting injectable SRLs (iSRLs) are a cornerstone of medical treatment in acromegaly and have demonstrated efficacy in attenuating serum GH and IGF-I levels, reducing tumor size, and improving symptoms [12]. However, only $56 \%$ of patients expressed satisfaction with current injectable treatments in 1 study [13]. Patients receiving iSRLs through deep tissue injection often report injection site pain, nodules, bruising, inflammation, and scarring as well as anxiety, frustration, and loss of independence. Additionally, many patients report missing work in order to receive injections and worsening of symptoms toward the end of the dosing interval $[5,9]$. The Acromegaly Treatment Satisfaction Questionnaire (Acro-TSQ) is a scale that was developed to provide a complete assessment of the disease and treatment burdens associated with acromegaly and for tracking the overall efficacy and unmet needs of new treatments for patients with acromegaly $[9,14]$. In 1 analysis employing the Acro-TSQ, two-thirds of patients who were biochemically responding to iSRLs reported ongoing acromegaly symptoms, with $>80 \%$ experiencing those symptoms all the time [15]. Avoiding injections, potentially by substituting an oral formulation, was mentioned as a top preference for new acromegaly treatments among $85 \%$ of respondents [13].

To address the patient burden associated with iSRLs, an oral formulation of octreotide has been developed. Oral octreotide capsules (OOC) combine octreotide with proprietary excipients (Transient Permeability Enhancer ${ }^{\circledR}$ ) to form an oily suspension of hydrophilic particles in a lipophilic medium [16, 17]. OOC are the first approved oral SRL for acromegaly in the United States and are indicated for long-term maintenance treatment in patients with acromegaly who have responded to and tolerated treatment with octreotide or lanreotide. Results of 2 complementary but distinct phase 3 multicenter trials examining the safety and efficacy of OOC have been reported. The first (CH-ACM-01) was an open-label, dose titration trial that included a large number of patients with acromegaly who were previously receiving iSRLs; the results from that trial have been reported previously [18]. The second trial, OOC-ACM-303 (CHIASMA OPTIMAL), was a randomized, double-blind, placebo-controlled (DPC) trial that served as the basis for US Food and Drug Administration approval of OOC as a long-term maintenance treatment in patients with acromegaly in whom prior treatment with SRLs has been shown to be effective and tolerated [19]. The objective of this report is to provide a more complete understanding of the safety and efficacy of OOC in patients with acromegaly, by comparing and contrasting the results obtained from the above trials with different designs.

\section{Comparison of methods}

Key differences in the 2 previously described protocols [ 18 , 19] are summarized in Table 1. The CHIASMA OPTIMAL trial required a more stringent inclusion cutoff for IGF-I ( $\leq 1.0 \times$ upper limit of normal [ULN]), and the CHIASMA OPTIMAL trial included a placebo arm. The CH-ACM-01 trial had an inclusion cutoff of IGF-I $<1.3 \times$ ULN and was open label. Primary endpoints varied, with both reflecting the different levels of biochemical response for entry criteria, as measured by IGF-I levels, with CHIASMA OPTIMAL using an average of 2 visits compared to a single measurement for the CH-ACM-01. The timing of baseline IGF-I measurements related to last dose of iSRL varied between the 2 trials, with the baseline measurement taken within 4 weeks of the last SRL injection for CH-ACM-01, and the baseline measurements being taken between 4 and 8 weeks from the last injection based on the prior iSRL dosing interval for a given patient for CHIASMA OPTIMAL (Fig. 1; Table 1). The imputation methods also differed between the 2 trials; CH-ACM-01 used last observation carried forward (LOCF), and CHIASMA OPTIMAL trial used worst observation carried forward (WOCF), or nonresponse imputation in the analysis of the primary endpoint (i.e., any patient who did not complete the full 9 months of treatment was considered a treatment failure regardless of the reason). For assessment of acromegaly symptom-related data, the Acromegaly Index of Severity (AIS) was used for CH-ACM-01, while for CHIASMA OPTIMAL, new or worsening signs and/or symptoms of acromegaly were monitored via adverse event (AE) reporting of AEs of special interest (AESIs; such as headache, perspiration, joint pain, fatigue, and soft tissue swelling, increases in blood pressure, and increases or decreases in blood sugar). 
a

Total Duration

(8-11 Months) ᄉ

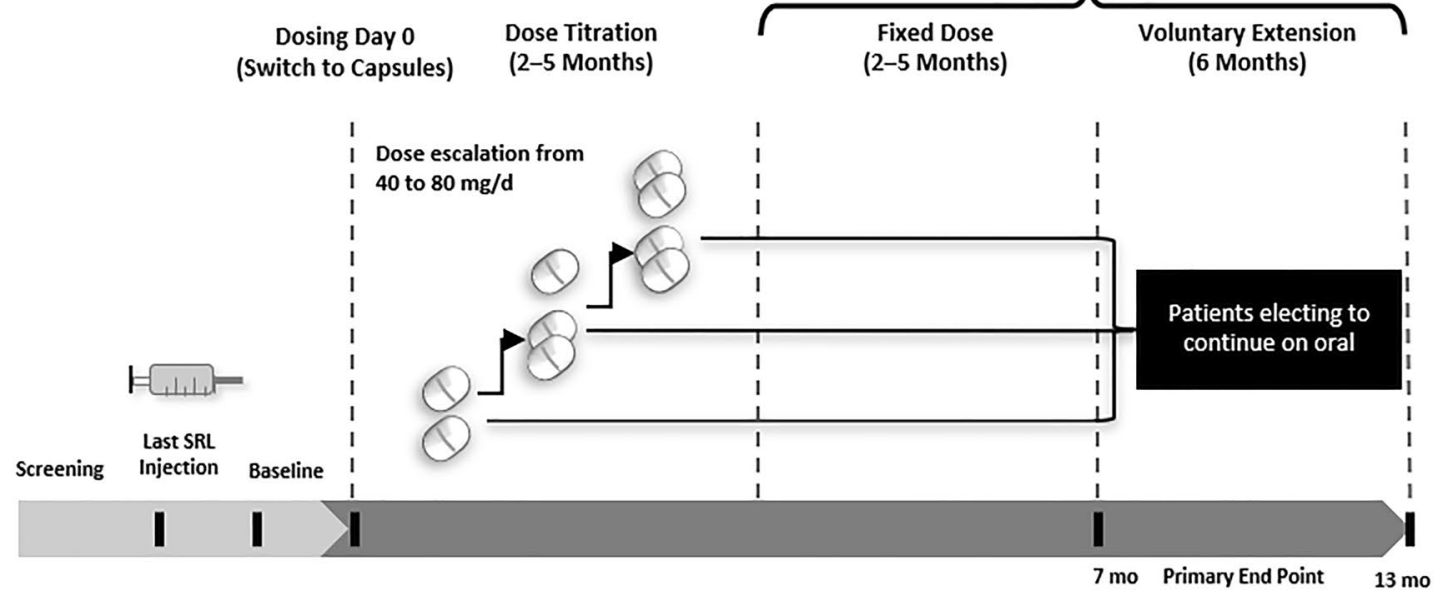

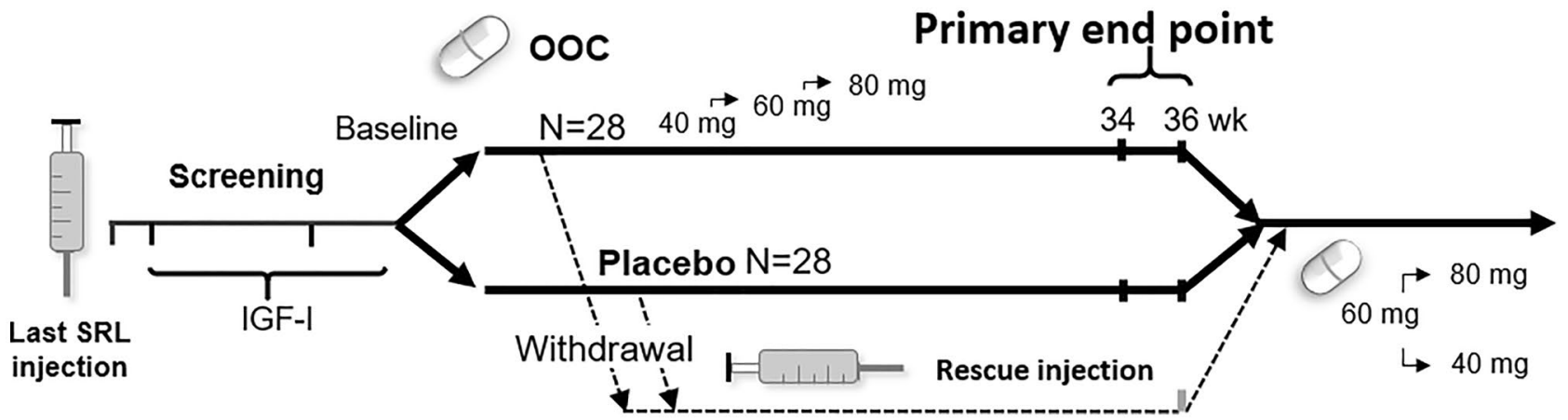

Fig. 1 Study design for phase 3 trials. The trial design for $\mathrm{CH}-$ ACM-01 (a) was open label and included an optional extension period while CHIASMA OPTIMAL (b) was DPC with an OLE.

Both trials had an optional extension phase. There were no dose restrictions for continuation into the 6-month extension period in CH-ACM-01. In CHIASMA OPTIMAL, patients could enter the open-label extension (OLE) if they completed 36 weeks on oral treatment (oral or placebo) or if they met the predefined withdrawal criteria (i.e., IGF-I $\geq 1.3$ $\times$ ULN and exacerbation of acromegaly clinical signs or symptoms). Upon entering the OLE phase, the starting dose for all patients was $60 \mathrm{mg}$ and was titrated based on IGF-I levels and/or signs and symptoms of acromegaly.

\section{Results}

A total of 235 individuals were screened for CH-ACM-01, of whom 80 (34\%) failed screening and 155 were enrolled. For CHIASMA OPTIMAL, 119 individuals were screened; $63(53 \%)$ failed screening and 56 of were enrolled into the
$D P C$ double-blind, placebo controlled, $O L E$ open-label extension, $O O C$ oral octreotide capsules, $S R L$ somatostatin receptor ligand

trial, 28 of whom were randomized to OOC. Baseline characteristics are described in Table 2. The baseline disease characteristics of patients enrolled in both trials were very similar despite the difference in biochemical values due to varying inclusion criteria $(\mathrm{IGF}-\mathrm{I}<1.3 \times \mathrm{ULN}$ for the $\mathrm{CH}-\mathrm{ACM}-01$ trial and $\mathrm{IGF}-\mathrm{I} \leq 1.0 \times \mathrm{ULN}$ for CHIASMA OPTIMAL).

For both trials, $>80 \%$ of patients reported active acromegaly symptoms at baseline despite long-term treatment with iSRLs (injectable long-acting forms of either octreotide or lanreotide) [18, 19]. In CH-ACM-01, at baseline, $81 \%$ of patients reported $\geq 1$ acromegaly symptom, $61 \%$ had $\geq 2$, and $43 \%$ had $\geq 3$ (Table 2 ). In the OOC group of CHIASMA OPTIMAL, at baseline, $82 \%$ of patients had $\geq 1$ symptom, $64 \%$ had $\geq 2$, and $36 \%$ had $\geq 3$. For the placebo group, $86 \%$ had $\geq 1$ symptom, $68 \%$ had $\geq 2$, and $50 \%$ had $\geq 3$ (Table 2 ).

Eligibility in the CH-ACM-01 trial was based on a screening visit prior to the baseline visit, and for CHIASMA 


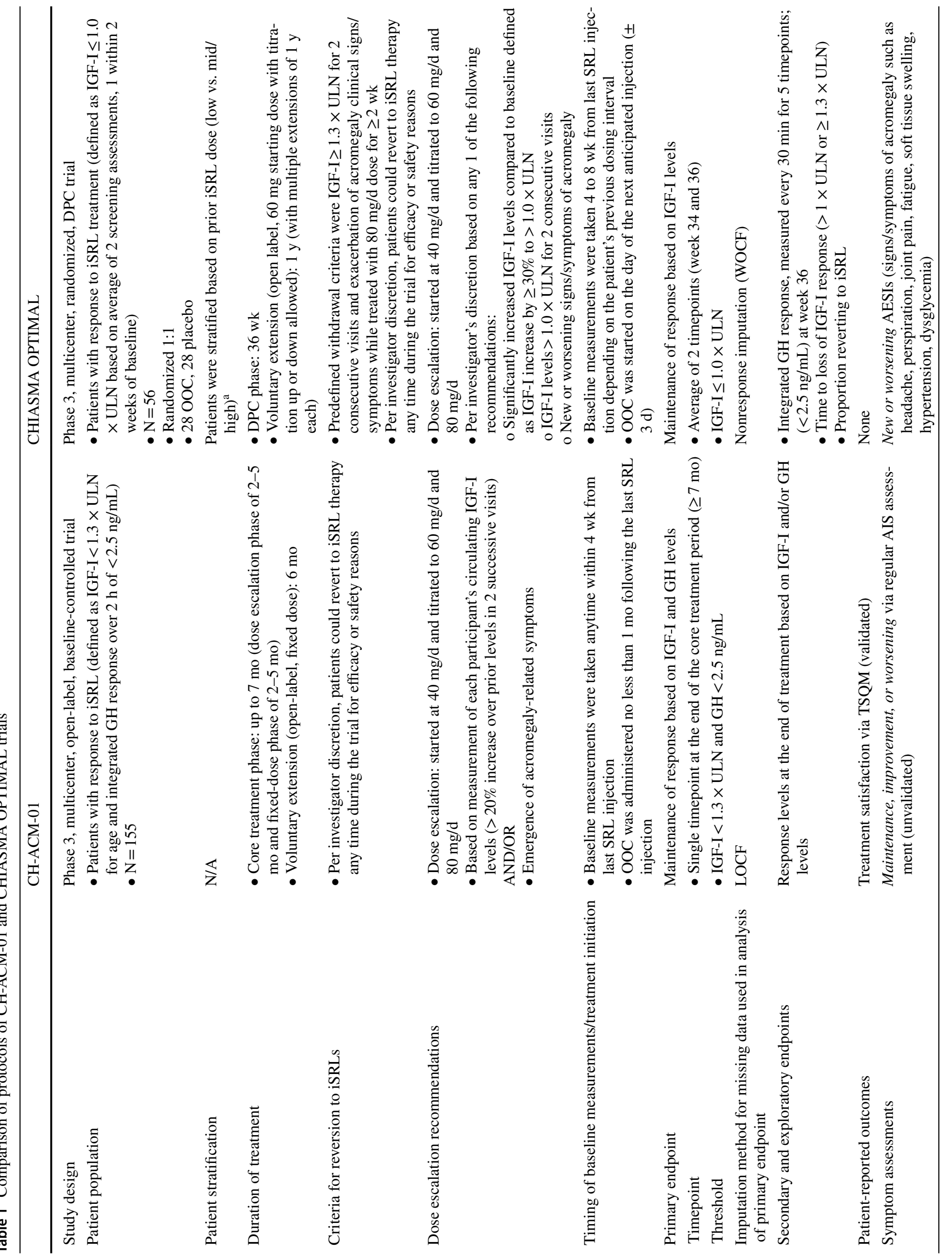


OPTIMAL, baseline IGF-I values were derived as an average of the second screening value and the baseline visit. Of interest, some patients had lost biochemical response between screening and the baseline visit in both trials: $12 \%$ of patients in $\mathrm{CH}-\mathrm{ACM}-01$ and $11 \%$ of patients in CHIASMA OPTIMAL no longer had IGF-I levels below the screening cutoff, suggesting variability in IGF-I levels in patients with biochemically controlled acromegaly (Table 2).

\section{Efficacy of OOC}

Both trials demonstrated the effectiveness of OOC in all prespecified analyses. Using LOCF imputation, $65 \%$ of patients in the CH-ACM-01 trial maintained response during the core phase (response defined as IGF-I $\leq 1.3 \times \mathrm{ULN}$ ), and $64 \%$ of patients in the OOC group of the CHIASMA OPTIMAL trial maintained response at the end of the DPC period (response defined as IGF-I $\leq 1.0 \times \mathrm{ULN}$ ). Using the WOCF imputation, maintenance of response was 53 and $58 \%$ in the CH-ACM-01 and CHIASMA OPTIMAL trials, respectively (Table 3 ) $[18,19]$. More than $85 \%$ (86 and $90 \%$ in the CH-ACM-01 and CHIASMA OPTIMAL trials, respectively) of the patients enrolled in the extension phases of each trial. Efficacy outcomes of the OOC treatment arms of CH-ACM-01 and CHIASMA OPTIMAL trials are summarized in Table 3. Efficacy outcome data for the CHIASMA OPTIMAL placebo group were reported previously [19].

Post hoc analysis using longitudinal IGF-I and GH measurements were used to provide a time-weighted average (TWA) that included all measurements for CH-ACM-01. TWA is an integrated measure of response over the entirety of the treatment period, which is more clinically relevant because fluctuations of IGF-I $( \pm 30 \%)$ are common [20-22]. Single timepoint responder analyses have limited utility in quantifying durability of response [23, 24]. Of the patients who entered the fixed-dose period, $80 \%$ completed the core period and were responders using TWA, in comparison to $75 \%$ using endpoint analysis. Additionally, $95 \%$ of patients maintained response throughout the extension period using TWA analysis versus $85 \%$ using endpoint analysis.

\section{Outcomes by prior injectable dose}

In $\mathrm{CH}-\mathrm{ACM}-01$, patients previously treated with low-mid doses versus high doses (dosing; Table 2) of long-acting SRLs had a 71.6 and $55.6 \%$ response rate at the end of treatment, respectively, but a formal between-group comparison was not performed. In CHIASMA OPTIMAL, maintenance of response was observed in $66.7 \%$ (4/6) of patients previously receiving low doses of iSRLs and $54.5 \%(12 / 22)$ of patients on medium-high injected doses. The treatment effect in CHIASMA OPTIMAL was consistent irrespective 
Table 2 Baseline characteristics of CH-ACM-01 and CHIASMA OPTIMAL trials
CH-ACM-01 ( $=155)$

CHIASMA OPTIMAL:

OOC Group $(\mathrm{n}=28)^{\mathrm{a}}$

\begin{tabular}{lll}
\hline Symptom burden at baseline & & \\
$\geq 1$ symptom, $\mathrm{n}(\%)$ & $125(81)$ & $23(82.1)$ \\
$\geq 2$ symptoms, $\mathrm{n}(\%)$ & $95(61)$ & $18(64.3)$ \\
$\geq 3$ symptoms, $\mathrm{n}(\%)$ & $67(43)$ & $10(35.7)$ \\
Mean baseline IGF-I levels, $\times$ ULN (SD) & $0.94(0.25)$ & $0.8(0.16)$ \\
Biochemical control at screening (cutoff) & $100 \%(\mathrm{IGF}-\mathrm{I}<1.3 \times$ ULN) & $100 \%(\mathrm{IGF-I} \leq 1.0 \times \mathrm{ULN})$ \\
Biochemical control at baseline, $\mathrm{n}(\%)$ & & \\
IGF-I $\leq 1.0 \times$ ULN & $95(61)$ & $27(96.4)$ \\
IGF-I $>1$ to $<1.3 \times$ ULN & $42(27)$ & $1(3.6)$ \\
IGF-I $\geq 1.3 \times$ ULN & $18(12)$ & 0 \\
Duration of acromegaly, n $(\%)$ & & \\
$<10 \mathrm{y}$ & $74(47.7)$ & $15(53.6)$ \\
$10-20 \mathrm{y}$ & $53(34.2)$ & $8(28.6)$ \\
$\geq 20 \mathrm{y}$ & $28(18.1)$ & $5(17.9)$ \\
Prior SRL treatment, $\mathrm{n}(\%)$ & & $3(10.7)$ \\
Octreotide low dose ${ }^{\mathrm{b}, \mathrm{c}}$ & $64(41.3)$ & $16(57.1)$ \\
Octreotide mid/high dose ${ }^{\mathrm{b}, \mathrm{c}}$ & $33(21.3)$ & $4(14.3)$ \\
Lanreotide low/mid dose $\mathrm{b}^{\mathrm{b}, \mathrm{c}}$ & $25(16.1)$ & $5(17.9)$ \\
Lanreotide high dose ${ }^{\mathrm{b}, \mathrm{c}}$ & $33(21.3)$ & $83.4(17.22)$ \\
Baseline weight kg $(\mathrm{SD})$ & $86.25(19.305)$ & $29.1(6.26)$ \\
BMI kg/m ${ }^{2}(\mathrm{SD})$ & $\mathrm{NC}$ & $6(21.4)$ \\
Diabetes mellitus, $\mathrm{n}(\%)$ & $29(18.7)$ & \\
\hline
\end{tabular}

$B M I$ body mass index, $G H$ growth hormone, IGF-I insulin-like growth factor I, $N C$ not calculated, $O O C$ oral octreotide capsules, $S R L$ somatostatin receptor ligand, $U L N$ upper limit of normal

${ }^{\text {a }}$ Data shown from the OOC group only in CHIASMA OPTIMAL. Placebo data were reported previously [19]

${ }^{b}$ Doses are defined as follows: For CH-ACM-01: octreotide low dose was considered to be 10 or $20 \mathrm{mg}$ every $4 \mathrm{wk}$; octreotide mid/high was considered to be 30,40, or $60 \mathrm{mg}$ every $3-4 \mathrm{wk}$; lanreotide low/mid was 30,60 , or $90 \mathrm{mg}$ every 3-4 wk; and lanreotide high was $120 \mathrm{mg}$ every $3-4 \mathrm{wk}$

${ }^{\mathrm{c}}$ For CHIASMA OPTIMAL, octreotide low dose was considered to be $10 \mathrm{mg}$ every 4 wk; octreotide mid/ high were considered to be 20 or $30 \mathrm{mg}$ every $4 \mathrm{wk}$; lanreotide low/mid were considered 60 or $90 \mathrm{mg}$ every 4 weeks or $120 \mathrm{mg}$ every 6-8 weeks; lanreotide high was considered to be $120 \mathrm{mg}$ every 4 weeks of prior dose of iSRL (odds ratio, 5.4 in low dose; 5.9 in medium-high dose).

Responders during the core treatment period of $\mathrm{CH}-$ ACM-01 $(n=82)$ had final OOC doses of $40 \mathrm{mg}(\mathrm{n}=48)$, $60 \mathrm{mg}(\mathrm{n}=19)$, and $80 \mathrm{mg}(\mathrm{n}=15)$. Breakdown by prior iSRL dose did not indicate a clear relationship with OOC dose in CH-ACM-01 (Fig. 2). This was not assessed in CHIASMA OPTIMAL because it is difficult to extrapolate dose correlations from CHIASMA OPTIMAL in the same manner as $\mathrm{CH}-\mathrm{ACM}-01$ owing to the limited sample size.

\section{Acromegaly symptoms}

$80 \%$ of patients entering the fixed-dose phase improved or maintained acromegaly symptoms (36\% maintained; $44 \%$ improved) at the end of the CH-ACM-01 trial. At the end of treatment, $80 \%$ of patients reported $\geq 1$ acromegaly symptom, $56 \%$ had $\geq 2$, and $38 \%$ had $\geq 3$. Acromegaly symptoms were not an efficacy endpoint for the CHIASMA OPTIMAL trial; however, AESIs were observed more frequently in patients receiving placebo than those receiving OOC (92.9\% vs. 53.6\%), indicating the emergence of acromegaly signs and symptoms while off treatment. The most common AESIs observed were arthralgia, hyperhidrosis, fatigue, carpal tunnel syndrome, and headache.

\section{Safety}

Adverse events were consistent with the well-established AE profile of iSRLs (Table 4). In the CH-ACM-01 trial, commonly reported AEs included gastrointestinal (e.g., nausea, diarrhea, dyspepsia, abdominal pain/distension, flatulence, vomiting), neurological (e.g., headache, dizziness), and musculoskeletal events (e.g., arthralgia, back pain) [18]. In the 
Table 3 Efficacy outcomes of CH-ACM-01 and CHIASMA OPTIMAL trials

\begin{tabular}{|c|c|c|}
\hline & $\mathrm{CH}-\mathrm{ACM}-01$ & CHIASMA OPTIMAL \\
\hline Primary endpoint (WOCF), \% & $53($ IGF-I $<1.3 \times \mathrm{ULN}$ and $\mathrm{GH}<2.5 \mathrm{ng} / \mathrm{mL})$ & 58 in OOC group $(\mathrm{IGF}-\mathrm{I} \leq 1.0 \times \mathrm{ULN})$ \\
\hline Primary endpoint (LOCF), \% & $\begin{array}{l}65 \text { (all patients; IGF-I }<1.3 \times \text { ULN and } \\
\mathrm{GH}<2.5 \mathrm{ng} / \mathrm{mL} \text { ) }\end{array}$ & 64 in OOC group $(\mathrm{IGF}-\mathrm{I} \leq 1.0 \times \mathrm{ULN})$ \\
\hline $\begin{array}{l}\text { Biochemical response in patients on study } \\
\text { drug who entered the fixed-dose period and } \\
\text { completed the trial, } \mathrm{n} / \mathrm{N}(\%)\end{array}$ & $82 / 110(75)$ & $16 / 21(76)$ \\
\hline $\begin{array}{l}\text { GH response (WOCF, among baseline } \\
\text { responders), \% }\end{array}$ & 67 & 78 in OOC group \\
\hline $\begin{array}{l}\text { GH response (LOCF, among baseline } \\
\text { responders), } \%\end{array}$ & 96 (complete responders only) & 96 in OOC group \\
\hline $\begin{array}{l}\text { Sustained response (WOCF, end of dose titra- } \\
\text { tion to end of trial), } \%\end{array}$ & 85 & 92 sustained response (no imputation needed) \\
\hline Completed the trial on study drug, $\%$ & 66 & 75 \\
\hline Patients electing to continue into the OLE, $\%$ & $\begin{array}{l}86 \text { (only completers were eligible to participate } \\
\text { in the optional extension) }\end{array}$ & $\begin{array}{l}\text { OOC group } \\
\text { - } 91 \text { (of patients }[n=19] \text { who completed the } \\
\text { trial on treatment) }\end{array}$ \\
\hline $\begin{array}{l}\text { Mean IGF-I levels at the end of treatment } \\
\text { (fixed-dose phase for CH-ACM-01 or DPC } \\
\text { for CHIASMA OPTIMAL) }\end{array}$ & $1.04 \times \mathrm{ULN}$ & $0.97 \times \mathrm{ULN}$ for the OOC group \\
\hline $\begin{array}{l}\text { Mean GH levels at the end of treatment (fixed- } \\
\text { dose phase for CH-ACM- } 01 \text { or DPC for } \\
\text { CHIASMA OPTIMAL) }\end{array}$ & $0.60 \mathrm{ng} / \mathrm{mL}$ & $0.6 \mathrm{ng} / \mathrm{mL}$ in the OOC group \\
\hline
\end{tabular}

$D P C$ double-blind, placebo-controlled, $G H$ growth hormone, IGF-I insulin-like growth factor I, LOCF last observation carried forward, $O L E$ open-label extension, $O O C$ oral octreotide capsules, $U L N$ upper limit of normal, WOCF worst observation carried forward

CHIASMA OPTIMAL trial, treatment-emergent AEs with $\geq 5 \%$ incidence that were more common in the OOC group than in the placebo group were diarrhea, nausea, abdominal discomfort, vomiting, dyspepsia, blood glucose increase, sinusitis, osteoarthritis, cholelithiasis, urinary tract infection, large intestine polyp, and pain.

In both trials, the majority of events occurred within the first 3 months of treatment, with AEs decreasing over time. There were no dose-related AEs observed in the $\mathrm{CH}$ ACM-01 trial. This assessment was not possible in CHIASMA OPTIMAL because of the small number of patients.

\section{Discussion}

The results of the CH-ACM-01 and CHIASMA OPTIMAL trials demonstrated consistent results in biochemical response, durability of response, and preference to continue treatment with OOC, with safety profiles that are similar to iSRLs $[18,19]$. The effect of OOC was notably preserved in both open-label (CH-ACM-01) and double-blind, placebocontrolled (CHIASMA OPTIMAL) trial designs. Both phase 3 trials have yielded unique information related to $\mathrm{OOC}$ as a treatment for acromegaly and provide information useful for clinicians treating acromegaly. The CH-ACM-01 trial enrolled a larger cohort of 155 patients, but CHIASMA
OPTIMAL's inclusion of a placebo control provides valuable insight into events that may be disease rather than treatment related.

These complementary trials enrolled similar acromegaly populations despite differences in inclusion criteria and the known variability of IGF-I levels [21, 25, 26]. Mean IGF-I levels at the start of the core treatment phase suggest that the enrolled populations are comparable between the 2 trials-for example, the cohort is representative of acromegaly patients who were previously biochemically responding to iSRLs. Periodic fluctuations above the ULN are common on SRLs, and the small difference in inclusion criteria did not appear to alter the phenotype of the patient population across the trials. Screening failures were slightly higher in CHIASMA OPTIMAL (53\%) compared to CH-ACM-01 $(34 \%)$, likely due to the more conservative entry criteria of IGF-I $\leq 1.0 \times$ ULN. The focus of the current report is comparison of active OOC treatment; thus, data from the placebo arm of CHIASMA OPTIMAL [19] have been only briefly touched upon.

Determination of the most effective dose of OOC as it relates to the prior iSRL dose was also assessed in these trials. Despite the higher rate of patients receiving mid/high iSRL doses in CHIASMA OPTIMAL and variations in dose escalation, maintenance of response was similar in the two trials. Post hoc analyses based on prior SRL dose were 


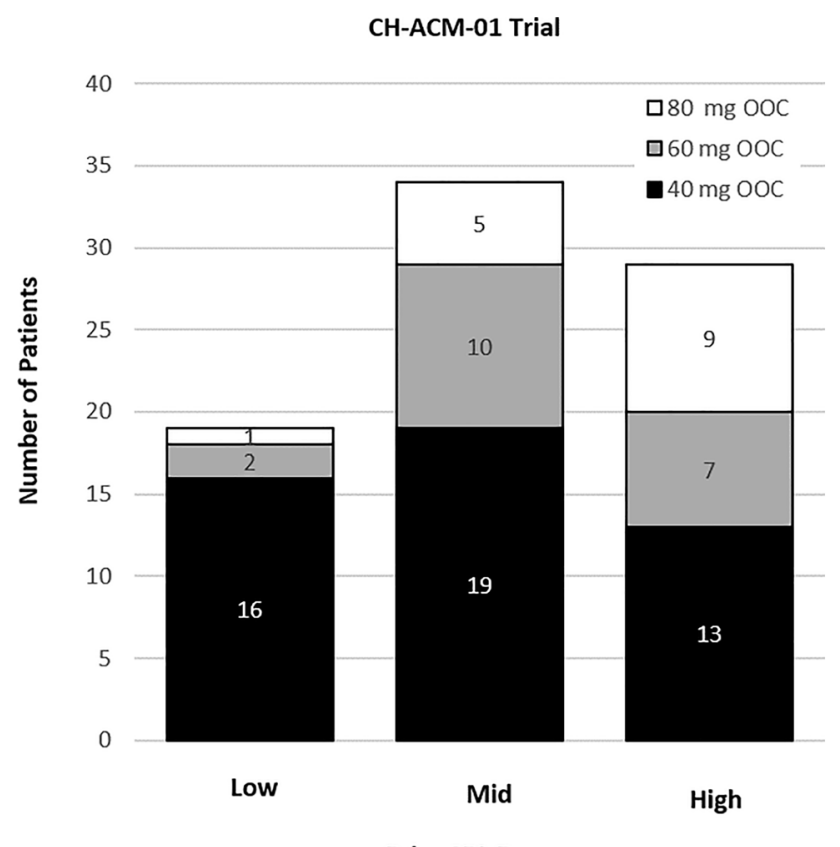

Prior SRL Dose

Fig. 2 Relationship of Prior iSRL Dose to Final OOC Dose in Responders in CH-ACM-01. For the CH-ACM-01 study, patients previously receiving a low, mid, or high stable dose of iSRL were titrated to a final OOC dose of 40,60 , or $80 \mathrm{mg}$. iSRL injectable somatostatin receptor ligand, $O O C$ oral octreotide capsules performed solely on patients completing the $\mathrm{CH}-\mathrm{ACM}-01$ trial as responders $(n=82)$. Of OOC responders previously on a high dose of iSRLs, $45 \%$ finished the core trial on the lowest tested dose of OOC (40 mg), and $69 \%$ on low-mid doses of OOC (40-60 mg). In the CHIASMA OPTIMAL trial, it is difficult to extrapolate dose correlations in the same manner due to the limited sample size. Further complicating analysis, the dose titration in CHIASMA OPTIMAL trial was driven by predefined criteria in the protocol for trial withdrawal requiring participants to have been on the maximum dose, $80 \mathrm{mg}$, for 2 consecutive visits with an IGF-I $\geq 1.3 \times$ ULN. In this manner, the dose escalation observed in CH-ACM-01 is more representative of standard clinical practice. Wear-off timing of previous long-acting iSRLs may influence dosing of OOC, as the placebo arm of CHIASMA OPTIMAL demonstrated a median of 16 weeks of continued control after stopping SRL injections [19], suggesting that a carryover effect of long-acting iSRLs may potentially delay need for OOC dose adjustments. However, neither of these trials could provide a clear indication of OOC dose based on prior iSRL dose.

Several currently approved iSRL therapies for acromegaly report outcomes using selective analysis in completers or less rigorous methods for handling missing data [27]. The 2 trials presented here assessed OOC efficacy using rigorous

Table 4 Overview of AEs in CH-ACM-01 and CHIASMA OPTIMAL trials

\begin{tabular}{|c|c|c|c|}
\hline & \multirow[t]{2}{*}{ CH-ACM-01 $(\mathrm{N}=155)$} & \multicolumn{2}{|c|}{ CHIASMA OPTIMAL $(\mathrm{N}=56)$} \\
\hline & & OOC $(n=28)$ & Placebo $(n=28)$ \\
\hline TEAEs, $\mathrm{n}$ & 1096 & 172 & 219 \\
\hline Patients with any TEAE, $\mathrm{n}(\%)$ & $134(86.5)$ & $28(100.0)$ & $27(96.4)$ \\
\hline Treatment-related TEAEs, $\mathrm{n}$ & 267 & 40 & 41 \\
\hline Patients with any treatment-related TEAE, $\mathrm{n}(\%)$ & $90(58.1)$ & $18(64.3)$ & $15(53.6)$ \\
\hline SAEs, $\mathrm{n}$ & 29 & 3 & 1 \\
\hline Patients with any SAE, n (\%) & $17(11.0)$ & $2(7.1)$ & $1(3.6)$ \\
\hline Treatment-related SAEs, $\mathrm{n}$ & 3 & 0 & 0 \\
\hline Patients with a treatment-related SAE, n (\%) & $2(1.3)$ & $0(0.0)$ & $0(0.0)$ \\
\hline Mild TEAEs, $\mathrm{n}$ & 691 & 118 & 150 \\
\hline Patients with maximum severity mild TEAEs, $\mathrm{n}(\%)$ & $31(20.0)$ & $11(39.3)$ & $8(28.6)$ \\
\hline Moderate TEAEs, $\mathrm{n}$ & 316 & 46 & 56 \\
\hline Patients with maximum severity moderate TEAEs, $\mathrm{n}(\%)$ & $61(39.4)$ & $14(50.0)$ & $12(42.9)$ \\
\hline Severe TEAEs, $\mathrm{n}$ & 84 & 8 & 13 \\
\hline Patients with maximum severity severe TEAEs, $\mathrm{n}(\%)$ & $42(27.1)$ & $3(10.7)$ & $7(25.0)$ \\
\hline TEAEs leading to study drug discontinuation, $\mathrm{n}$ & 41 & 5 & 1 \\
\hline Patients with any TEAE leading to study drug discontinuation, $\mathrm{n}(\%)$ & $21(13.5)$ & $2(7.1)$ & $1(3.6)$ \\
\hline Treatment-related TEAEs leading to study drug discontinuation, $\mathrm{n}$ & 34 & 5 & 0 \\
\hline $\begin{array}{l}\text { Patients with a treatment-related TEAE leading to study drug discontinu- } \\
\text { ation, } \mathrm{n}(\%)\end{array}$ & $17(11.0)$ & $2(7.1)$ & $0(0.0)$ \\
\hline TEAEs leading to death, $\mathrm{n}$ & 9 & 0 & 0 \\
\hline Patients with any TEAE leading to death, $\mathrm{n}(\%)$ & $2(1.3)$ & $0(0.0)$ & $0(0.0)$ \\
\hline
\end{tabular}

$A E$ adverse event, $S A E$ serious adverse event, $T E A E$ treatment-emergent adverse event 
and conservative approaches to account for missing data, including LOCF (CH-ACM-01) and WOCF (CHIASMA OPTIMAL) as primary endpoints. Nevertheless, both trials showed consistent and effective maintenance of biochemical response in patients with acromegaly. For CH-ACM-01, an additional post hoc TWA, which may provide a more accurate and clinically meaningful assessment, showed an even greater response as compared with end-of-treatment analysis in the fixed-dose population at the end of the extension phase [14]. Additionally, $80 \%$ of the patients entering the fixed-dose phase in CH-ACM-01 maintained or improved acromegaly symptoms from baseline to the end of treatment. This was observed despite the majority of patients demonstrating biochemical response at baseline from prior iSRLs. The reduction in symptoms at the end of the trial was possibly due to more frequent capsule dosing that could result in more consistent circulating octreotide levels, helping to reduce breakthrough symptoms that are seen with the longer dosing intervals used with iSRLs.

In both trials, the majority of patients who were fully or partially responding at baseline maintained response at the end of the trial. Importantly, a portion of patients in $\mathrm{CH}$ ACM-01 who were not biochemically controlled at baseline demonstrated biochemical response by the end of the trial; the single patient in CHIASMA OPTIMAL who had an IGF-I $>1.0 \times$ ULN at baseline, improved by the end of the trial. These data indicate that treatment with OOC can maintain biochemical control of acromegaly and may additionally help achieve control in patients who have elevated IGF-I levels while receiving iSRLs. Patients should be closely monitored to ensure long-term biochemical control, as results from these trials highlight the variability of IGF-I levels in patients with acromegaly. However, for optimal dosing and maintenance of response, it is important that patients take OOC with water $\geq 1 \mathrm{~h}$ before a meal or $\geq 2 \mathrm{~h}$ after a meal. Importantly, if biochemical control was lost while a participant was receiving OOC, reversion to their previous iSRL dose in CHIASMA OPTIMAL resulted in regain of control within 4 weeks, or 1 injection cycle [19]. Among the patients who completed the dose adjustment period of the 2 trials and were stabilized on a fixed dose of OOC, most achieved a durable response and entered the voluntary extension phase. Notably, patient-reported symptoms should be considered in dose titration decisions, as symptoms reported by health care providers and symptoms reported by patients are often not congruent, particularly in regards to frequency, severity, and pattern of symptoms [28].

OOC were found to be safe and well tolerated in both trials. The most common TEAEs were gastrointestinal, neurological, and musculoskeletal AEs, and were consistent with the known safety profile of iSRLs. Furthermore, no dose-related AEs were observed. In the CHIASMA OPTIMAL trial, approximately double the number of AESIs were observed in the placebo group, including higher rates of arthralgia, hyperhidrosis, fatigue, and peripheral swelling, mirroring the loss of biochemical control observed in these patients after withdrawal of active treatment.

Despite disease control achieved with current iSRL options, there remains an unmet need for patients with acromegaly receiving regular injections due to treatment inconvenience, injection-related pain, and complications $[5,9,13$, 28]. Many patients with acromegaly desire an alternative to injections, in the form of an oral treatment, to alleviate some of these burdens [13]. The oral octreotide formulation precludes all possibility of injection site reactions that are commonly encountered with existing iSRLs. OOC represents a safe and effective treatment option for many patients with acromegaly who require medical therapy, allowing patients who are currently responding to iSRL therapy to be safely transitioned to oral therapy if they desire, with the potential to decrease the burden and costs associated with injections.

Acknowledgements The authors thank the trial coordinators, coinvestigators, patients, and families who participated in the trials. Medical writing assistance and revision of the manuscript under the direction of the authors was provided by PRECISIONscientia, which was supported by Chiasma, Inc.

Author contributions All authors have been personally and actively involved in substantial work leading to the paper and will take public responsibility for its content. The first draft of the manuscript was written by Artak Labadzhyan with editorial support, and all authors commented on previous versions of the manuscript. All authors read and approved the final manuscript.

Funding The trial was funded by Chiasma, Inc. (Needham, MA).

Data availability The datasets generated during and/or analyzed during the current trial are available from the corresponding author on reasonable request.

\section{Declarations}

Conflict of interest AL reports no conflicts of interest. LBN served as research support for Chiasma and received grant support from and served as a consultant for Ipsen. MF received a research grant to Oregon Health and Science University as principal investigator for Crinetics, Chiasma, Ionis, Novartis, Recordati and served as a scientific consultant for Crinetics, Chiasma, Ionis, Ipsen, Novartis, Pfizer, and Recordati. MBG received research support from Chiasma, Corcept, Crinetics, Ipsen, Novartis, Opico, Pfizer, Strongbridge, Teva, and Novo Nordisk and served as a scientific consultant for Chiasma and Novo Nordisk. MM received research grant to institution from Chiasma, Novartis, and Crinetics and received a consultation honorarium from Chiasma. LK served as a clinical trial principal investigator for Chiasma and Ionis and served as a consultant for Pfizer. SLS served as site principal investigator, steering chair, and consultant for Chiasma and Novartis. YG received funding in the form of a research grant from Pfizer and was compensated for serving as principal investigator of research grants to Tel Aviv-Sourasky Medical Center from Chiasma and Strongbridge Biopharma, and also received consultation fees from Tiburio and lecture fees from CTS. NB reports no conflicts of interest. MB received a research grant from Ispen and lecture fees from 
Ispen, Novartis, Pfizer, and Recordati, and also served as an advisory board member for Novartis, Pfizer, and Recordati. AH, WHL, GP are employees of Chiasma. CJS received consultancy fees and speaker honoraria from Chiasma, Pfizer, Ipsen, and Crinetics.

Ethical approval This trial was performed in accordance with the principles stated in the Declaration of Helsinki. Prior to starting the trials, ethical approval was obtained for all protocols from the local Institutional Review Board or other appropriate ethics committee to confirm the trials meet national and international guidelines for research on humans.

Consent to participate Informed consent was obtained from all individual participants included in the trials.

Open Access This article is licensed under a Creative Commons Attribution 4.0 International License, which permits use, sharing, adaptation, distribution and reproduction in any medium or format, as long as you give appropriate credit to the original author(s) and the source, provide a link to the Creative Commons licence, and indicate if changes were made. The images or other third party material in this article are included in the article's Creative Commons licence, unless indicated otherwise in a credit line to the material. If material is not included in the article's Creative Commons licence and your intended use is not permitted by statutory regulation or exceeds the permitted use, you will need to obtain permission directly from the copyright holder. To view a copy of this licence, visit http://creativecommons.org/licenses/by/4.0/.

\section{References}

1. Katznelson L, Atkinson JL, Cook DM, Ezzat SZ, Hamrahian AH, Miller KK (2011) American Association of Clinical Endocrinologists medical guidelines for clinical practice for the diagnosis and treatment of acromegaly-2011 update. Endocr Pract 17:1-44. https://doi.org/10.4158/ep.17.s4.1

2. Katznelson L, Laws ER Jr, Melmed S, Molitch ME, Murad MH, Utz A, Wass JAH (2014) Acromegaly: an Endocrine Society clinical practice guideline. J Clin Endocrinol Metab 99:3933-3951. https://doi.org/10.1210/jc.2014-2700

3. Melmed S (2009) Acromegaly pathogenesis and treatment. J Clin Invest 119:3189-3202. https://doi.org/10.1172/jci39375

4. Melmed S (2020) Pituitary-tumor endocrinopathies. N Engl J Med 382:937-950. https://doi.org/10.1056/NEJMra1810772

5. Strasburger CJ, Karavitaki N, Störmann S, Trainer PJ, Kreitschmann-Andermahr I, Droste M, Korbonits M, Feldmann B, Zopf K, Sanderson VF, Schwicker D, Gelbaum D, Haviv A, Bidlingmaier M, Biermasz NR (2016) Patient-reported outcomes of parenteral somatostatin analogue injections in 195 patients with acromegaly. Eur J Endocrinol 174:355-362. https://doi.org/10. 1530/eje-15-1042

6. Fleseriu M (2011) Clinical efficacy and safety results for dose escalation of somatostatin receptor ligands in patients with acromegaly: a literature review. Pituitary 14:184-193. https://doi.org/ 10.1007/s11102-010-0282-z

7. Gadelha MR, Kasuki L, Lim DST, Fleseriu M (2019) Systemic complications of acromegaly and the impact of the current treatment landscape: an update. Endocr Rev 40:268-332. https://doi. org/10.1210/er.2018-00115

8. Colao A, Grasso LFS, Giustina A, Melmed S, Chanson P, Pereira AM, Pivonello R (2019) Acromegaly Nat Rev Dis Primers 5:20. https://doi.org/10.1038/s41572-019-0071-6
9. Fleseriu M, Fogelfeld L, Gordon MB, Sisco J, Crosby RD, Ludlam WH, Haviv A, Mathias SD (2020) An evaluation of the Acromegaly Treatment Satisfaction Questionnaire (Acro-TSQ) in adult patients with acromegaly, including correlations with other patient-reported outcome measures: data from two large multicenter international studies. Pituitary 23:347-358. https://doi.org/ 10.1007/s11102-020-01038-y

10. Fleseriu M, Biller BMK, Freda PU, Gadelha MR, Giustina A, Katznelson L, Molitch ME, Samson SL, Strasburger CJ, van der Lely AJ, Melmed S (2021) A Pituitary Society update to acromegaly management guidelines. Pituitary 24:1-13

11. Lim DS, Fleseriu M (2017) The role of combination medical therapy in the treatment of acromegaly. Pituitary 20:136-148. https:// doi.org/10.1007/s11102-016-0737-y

12. Carmichael JD, Bonert VS, Nuño M, Ly D, Melmed S (2014) Acromegaly clinical trial methodology impact on reported biochemical efficacy rates of somatostatin receptor ligand treatments: a meta-analysis. J Clin Endocrinol Metab 99:1825-1833. https:// doi.org/10.1210/jc.2013-3757

13. Liu S, Adelman DT, Xu Y, Sisco J, Begelman SM, Webb SM, Badia X, Thethi TK, Fonseca V, Shi L (2018) Patient-centered assessment on disease burden, quality of life, and treatment satisfaction associated with acromegaly. J Investig Med 66:653-660. https://doi.org/10.1136/jim-2017-000570

14. Fleseriu M, Melmed S, Mangal B, Strasburger CJ, Biermasz NR (2016) Longitudinal assessment of response to treatment with oral octreotide capsules in patients with acromegaly: post-hoc analysis of a phase 3 trial. Endocrine Abstracts 41:GP151. https://doi.org/ 10.1530/endoabs.41.GP151

15. Fleseriu M, Molitch M, Dreval A, Biermasz NR, Gordon MB, Crosby RD, Ludlam WH, Haviv A, Gilgun-Sherki Y, Mathias SD (2021) Disease and treatment-related burden in patients with acromegaly who are biochemically controlled on injectable somatostatin receptor ligands. Front Endocrinol (Lausanne) 12:627711

16. Tuvia S, Atsmon J, Teichman SL, Katz S, Salama P, Pelled D, Landau I, Karmeli I, Bidlingmaier M, Strasburger CJ, Kleinberg DL, Melmed S, Mamluk R (2012) Oral octreotide absorption in human subjects: comparable pharmacokinetics to parenteral octreotide and effective growth hormone suppression. J Clin Endocrinol Metab 97:2362-2369. https://doi.org/10.1210/jc.2012-1179

17. Tuvia S, Pelled D, Marom K, Salama P, Levin-Arama M, Karmeli I, Idelson GH, Landau I, Mamluk R (2014) A novel suspension formulation enhances intestinal absorption of macromolecules via transient and reversible transport mechanisms. Pharm Res 31:2010-2021. https://doi.org/10.1007/s11095-014-1303-9

18. Melmed S, Popovic V, Bidlingmaier M, Mercado M, van der Lely AJ, Biermasz N, Bolanowski M, Coculescu M, Schopohl J, Racz K, Glaser B, Goth M, Greenman Y, Trainer P, Mezosi E, Shimon I, Giustina A, Korbonits M, Bronstein MD, Kleinberg D, Teichman S, Gliko-Kabir I, Mamluk R, Haviv A, Strasburger C (2015) Safety and efficacy of oral octreotide in acromegaly: results of a multicenter phase III trial. J Clin Endocrinol Metab 100:1699-1708. https://doi.org/10.1210/jc.2014-4113

19. Samson SL, Nachtigall LB, Fleseriu M, Gordon MB, Bolanowski M, Labadzhyan A, Ur E, Molitch M, Ludlam WH, Patou G, Haviv A, Biermasz N, Giustina A, Trainer PJ, Strasburger CJ, Kennedy L, Melmed S (2020) Maintenance of acromegaly control in patients switching from injectable somatostatin receptor ligands to oral octreotide. J Clin Endocrinol Metab 105:e3785-e3797. https://doi.org/10.1210/clinem/dgaa526

20. Erotokritou-Mulligan I, Eryl Bassett E, Cowan DA, Bartlett C, Milward P, Sartorio A, Sönksen PH, Holt RI (2010) The use of growth hormone $(\mathrm{GH})$-dependent markers in the detection of $\mathrm{GH}$ abuse in sport: physiological intra-individual variation of IGF-I, type 3 pro-collagen (P-III-P) and the GH-2000 detection score. Clin Endocrinol (Oxf) 72:520-526 
21. Milani D, Carmichael JD, Welkowitz J, Ferris S, Reitz RE, Danoff A, Kleinberg DL (2004) Variability and reliability of single serum IGF-I measurements: impact on determining predictability of risk ratios in disease development. J Clin Endocrinol Metab 89:22712274. https://doi.org/10.1210/jc.2003-032150

22. Nguyen TV, Nelson AE, Howe CJ, Seibel MJ, Baxter RC, Handelsman DJ, Kazlauskas R, Ho KK (2008) Within-subject variability and analytic imprecision of insulinlike growth factor axis and collagen markers: Implications for clinical diagnosis and doping tests. Clin Chem 54:1268-1276

23. van Esdonk MJ, Burggraaf J, van der Graaf PH, Stevens J (2020) Model informed quantification of the feed-forward stimulation of growth hormone by growth hormone-releasing hormone. Br J Clin Pharmacol 86:1575-1584. https://doi.org/10.1111/bcp.14265

24. van Esdonk MJ, van Zutphen EJM, Roelfsema F, Pereira AM, van der Graaf PH, Biermasz NR, Stevens J, Burggraaf J (2018) How are growth hormone and insulin-like growth factor-1 reported as markers for drug effectiveness in clinical acromegaly research? A comprehensive methodologic review. Pituitary 21:310-322. https://doi.org/10.1007/s11102-018-0884-4

25. Rosario PW (2010) Normal values of serum IGF-1 in adults: results from a Brazilian population. Arquivos Brasileiros de Endocrinologia Metabologia 54:477-481
26. Skjaerbaek C, Frystyk J, Kaal A, Laursen T, Møller J, Weeke J, Jørgensen JO, Sandahl Christiansen J, Orskov H (2000) Circadian variation in serum free and total insulin-like growth factor (IGF)-I and IGF-II in untreated and treated acromegaly and growth hormone deficiency. Clin Endocrinol (Oxf) 52:25-33. https://doi.org/ 10.1046/j.1365-2265.2000.00876.x

27. Colao A, Bronstein MD, Freda P, Gu F, Shen CC, Gadelha M, Fleseriu M, van der Lely AJ, Farrall AJ, Hermosillo Reséndiz K, Ruffin M, Chen Y, Sheppard M (2014) Pasireotide versus octreotide in acromegaly: a head-to-head superiority study. J Clin Endocrinol Metab 99:791-799. https://doi.org/10.1210/jc.2013-2480

28. Geer EB, Sisco J, Adelman DT, Ludlam WH, Haviv A, Gelbaum D, Liu S, Mathias SD, Shi L (2020) Observed discordance between outcomes reported by acromegaly patients and their treating endocrinology medical provider. Pituitary 23:140-148. https:// doi.org/10.1007/s11102-019-01013-2

Publisher's Note Springer Nature remains neutral with regard to jurisdictional claims in published maps and institutional affiliations. 